\title{
ALGUNOS ARTISTAS Y ARTESANOS DEL MEXICO DE CERVANTES DE SALAZAR (1550-1560)
}

\author{
P O R
}

\section{SALVA DOR CRUZ}

El afortunado hallazgo del protocolo de Cristóbal de Tapia en el Archivo General de Notarías, de Puebla, ${ }^{1}$ nos permite reconstruir un momento de la intensa "variedad de oficios" metropolitana del medio siglo xvi.

Aparece Tapia como escribano de número de la ciudad de México hacia 1550, y para fines del 61 ya lo encontramos desempeñando su oficio en el pueblo de Tepeaca. Bien podemos suponer que llevó consigo el protocolo de la capital, pues esto explicaria el que se encuentre sumado al de su cargo posterior, donde hasta la fecha ha permanecido sin investigar y por lo tanto inédito.

Como quiera que en 1554 estampara sus Tres diálogos latinos el maestro Cervantes de Salazar, hemos querido relacionar nuestra exhumación con la brillante época del primer cronista de la ciudad de México. Por otra parte, preferimos no dejar en el tintero varios oscuros nombres de la artesania, con el deseo de que puedan ser útiles a la investigación histórica en general.

\section{PINTORES}

Al decir de fray Jerónimo de Mendieta, el barrio de Santa María la Redonda —antiguo calpulli de Cuepopan- era "el principal de los indios

1 Archivo General de Notarías, Puebla. Protocolo de Tepeaca. Siglo xvi. Escribano: Cristóbal de Tapia. 
mexicanos". ${ }^{2}$ No es de extrañarse, pues, que los tres pintores indigenas que en seguida se nombran, fueran vecinos al dicho barrio. Aún más, en la escritura donde aparecen, se hace constar que los testigos son indios, "por no poderse hallar españoles". 3

Marcos Griego, pintor, 1553.

Compró casa en el barrio de Santa María. Firmaba "de Una señl q acostumbra hazy", consistente en una cruz entre dos cabecitas de león." Francisco Tlapaltecatl, pintor, 1553.

Vecino del anterior. ${ }^{\mathrm{s}}$

Pedro Cuautl, pintor, 1553.

Vecino de los anteriores. ${ }^{B}$

Ese mismo año aparecen dos equipos indígenas al servicio del Oidor licenciado Herrera. El primero, procedente del barrio de Santiago (Tlaltelolco), habia "dado yndios e pintado y echo pintar cyertas piezas de ia casa del dho señor oydor asy en la nueva como en la vieja e otras pinturas". 7 El otro los formaban indios "de la parte de México", y se encargó de pintar "el cuarto nuevo... q cae hazia la calle de Tacuba". ${ }^{8}$ Al concluir, todos se dieron por contentos y pagados.

\section{CONSTRUCTORES}

Aun cuando no tropezamos con ningún maestro mayor, en cambio seguimos comprobando la innegable contribución de la "mano de obra india", que dijera don Manuel Romero de Terreros."

Asi logramos destacar, en 1551, seis equipos de artifices indigenas, que "han dado piedra, madera, vigas, peones y otras cosas para las casas

2 Mendieta, Fr. Jerónimo de. Historia Eclesiástica Indiana. México, 1870.

3 Venta de marcos griego yndio De las casas q. le vendio grigorio. Año de 1553, foja 11 vto.

4 Ibid., foja 10 fte.

5 Ibid., foja 11 vto.

6 Ibid.

7 Contento de los indios de Santiago. Año de 1553, foja $18 \mathrm{fte.}$

8 Contento de los indios de la parte de México. Ibid., foja 19 fte.

9 Romero de Terreros, Manuel. Historia sintética del arte colonial. México, 1922. 
que el licencyado herrera hizo en el tianguis de Sn Juo". 10 Se trataba de naturales de Tlalmanalco, ${ }^{11}$ Tepoztlán, ${ }^{12}$ Ayotzingo, ${ }^{13}$ Tula, ${ }^{14}$ Barrio de Santiago, ${ }^{16}$ e Ixtapaluca. ${ }^{16}$ Después de la obra, todos se dieron por contentos y pagados.

\section{ORFEBRES}

El arte de la platería en México - para citar el clásico título de Lawrence Anderson-, puede hacer suyos los siguientes nombres:

Francisco Remón de Cardona, platero, 1551.

Poseía y arrendó "unas casas en la calle detras del espital de las buas en la calle q va a dar a Sn Pablo". Sabía firmar. ${ }^{17}$

Andrés de Buytrago, Francisco de Arella y Juán López, plateros. 1551.

Por cuentas, se hallaban "presos en la cárcel real desta corte", donde otorgaron poder. Sabían firmar. ${ }^{18}$

Francisco de Salcedo, Platero, 1552.

Vecino de la ciudad, sin mayor indicación. ${ }^{10}$

Felipe de Mociana, batihoja, 1560.

Vecino de Sevilla, estante en México. Casado con Luisa de Armijo, vecina de aquella ciudad en el barrio de Triana. ${ }^{20}$

Alonso de Morales, batihoja, circa 1560.

Estuvo casado con Catalina de Ribas, quien en marzo de 1560 lo cita como difunto. ${ }^{21}$

10 Contento de los indios de Tlalmanalco. Año de 1551, foja 64 fte.

11 Ibid.

12 Contento de los principales de Tepuztlán. Ibid., foja 64 vto.

13 Contento de los principales de Ayucingo. Ibid., foja 65 fte.

14 Contento de los principales de Tula. Ibid., foja 65 vto.

15 Contento de los principales del Barrio de Santiago. Ibid., foja 66 fte.

16 Contento de los principales de Iztapaluca. Ibid., foja 67 fte.

17 Arrendamiento. Ibid., foja 41 fte.

18 Poder. Ibid., foja 57 fte.

19 Servicio. Año de 1552, foja 25 vto.

20 Poder. Año de 1560, foja 1 fte.

21 Dote. Ibid., foja 11 fte. 


\section{UN VIDRIERO}

De un gremio que no llegó a florecer en la metrópoli, apenas si perdura el nombre de algún artesano. El nuestro es:

RoDRIGo DE EsPINOSA, vidriero, 1557.

Declaró ser vecino de la ciudad de México, estante en el pueblo de Tepeaca. Sabía firmar. ${ }^{22}$ Curiosamente, recordemos que otro fabricante del mismo apellido fue el primer vidriero establecido en puebla, en 1542.

\section{HERREROS}

Por lo que se ve, también en la industria del hierro fue muy apreciable la mano indigena :

LUIS DUEÑ̄as, hornero, 1550.

Vecino de la ciudad, sin mayor indicación, ${ }^{23}$

Bernaldino Ortiz, herrero, 1551.

Poseía casas en el barrio de Santa Catarina. ${ }^{24}$

Diego YaviL, oficial de afinador, fundidor y hornero, $y$

PEDRo AyOTL, oficial de fundidor y hornero, 1553.

El primero, natural de Tlaxcala, y el segundo, de Yopecingo. Se concertaron para trabajar "en las mynas de Izmyquylpa", de Ortuño de Ibarra. ${ }^{25}$

Juan Guavil, fundidor y hornero, 1553.

Natural de México al barrio de San Sebastián. Entró en servicio de Diego de Ibarra en las minas de las Zacatecas. ${ }^{20}$

\section{VARIA}

Hernán Gutrérrez, catpintero, 1550.

Vivia en la calle de Santo Domingo. ${ }^{27}$

22 Obligación. Año de 1557, legajo 10, foja 7 fte.

23 Poder General. Año de 1550, foja 26 fte.

24 Arrendamiento. Año de 1551, foja 8 fte.

25 Servicio. Año de 1553, foja 1 fte.

26 Servicio. Ibid., foja 1 vto.

27 Remate. Año de 1550, foja 41 fte. 
Fabián Tecpan y Antón Tlatolsuchitl, indios, carpinteros, 1553. Vecinos de los pintores indigenas citados, del barrio de Santa María. ${ }^{28}$ Diego Pérez, "texedor de terciopelo", 1551. ${ }^{20}$ PEDRo de BuERas, sedero, 1553. ${ }^{30}$

LuYs Machuca, sedero, 1553. 31

Graviel Ruiz, sedero, 1555. ${ }^{32}$

Domyngo Hernández, "maestro denseñar a danzar y escrevyr", 1558. Declaró ser vecino de México, estante de Tepeaca. ${ }^{33}$

Tal es la breve nómina de artistas y artesanos que arrojó el oficio del escribano Cristóbal de Tapia. No está por demás decir que, sumados al protocolo de Tepeaca, también se encuentran parte de los de Michoacán, Querétaro y Antequera del Valle de Oaxaca, aunque infortunadamente de muy poca monta. La escribanía de Tapia era, al parecer, la de un trajinante.

28 Vide 3.

29 Venta. Año de 1551, foja 59 fte.

30 Poder. Año de 1553, foja 13 fte.

31 Poder. Ibid., foja 20 fte.

32 Servicio. Año de 1555, pliego suelto.

33 Obligación. Año de $1558,2^{\bullet}$ legajo, foja 34 vto. 